\title{
Nilai Luhur Serat Wulangreh Pupuh Gambuh Membangun Karakter Generasi Milenial
}

\author{
Dwi Retnowati \\ SMP Negeri 2 Sampang Kabupaten Cilacap \\ email: $\underline{\text { dretnowati21@gmail.com }}$
}

\begin{abstract}
Abstrak
Serat Wulangreh adalah karya sastra Jawa karya Sri Susuhunan Pakubuwana IV yang penuh dengan ajaran nilai moral yang tinggi. Nilai moral yang terkandung didalamnya merupakan sumber pendidikan karakter yang berbasisi pada kearifan lokal. Serat Wulangreh pupuh Gambuh merupakan bahan ajar pada mata pelajaran Bahasa Jawa kelas VIII di tingkat SMP/MTs. Siswa kelas tersebut diduduki oleh generasi milenial. Tujuan dari penelitian ini adalah mengungkapkan nilai-nilai luhur yang terkandung di dalam serat Wulangreh pupuh Gambuh sebagai sumber pendidikan karakter bagi generasi milenial. Jenis penelitian ini adalah penelitian kualitatif dengan fokus pada pendidikan karakter yang dibangun dan diterapkan pada generasi milenial. Metode penelitian yang digunakan adalah metode deskriptif kualitatif. Analisis data dilakukan secara deskriptif. Serat Wulangreh dibongkar isinya untuk menentukan nilai-nilai luhur yang terkandung di dalamnya. Dari nilai-nilai luhur tersebut ditarik kesimpulan nilai karakter yang termuat di dalamnya. Hasil penelitian ditemukan kandungan teks yang layak dijadikan sumber pendidikan karakter bagi generasi milenial meliputi jangan menyombongkan diri atas kekuatan, keluhuran, dan kepandaiain yang dimiliki; jangan merasa serba tahu; jangan suka disanjung, mau mendengarkan nasehat; harus jujur, sabar, cermat, hati-hati, dan waspada; selektif memilih teman; meraih kepercayaan orang dengan cara yang baik. Hal tersebut menjadi sumber pendidikan karakter bagi generasi milenial sebagai bekal dalam menjalani kehidupan.
\end{abstract}

Kata kunci: Nilai Moral, Nilai Luhur, Nilai Karakter, Generasi Milenial

\begin{abstract}
Serat Wulangreh is a Javanese literature worked by Sri Susuhunan Pakubuwana IV which is full of high moral values. These moral values are a source of character education based on local wisdom. Serat Wulangreh Pupuh Gambuh is a teaching material in Javanese subject for grade VIII students of Junior High School, which are occupied by the millennial generation. Thus, the purpose of this research was to reveal the noble values contained in the Serat Wulangreh Pupuh Gambuh as a source of character education for the millennial generation. This study is categorized into qualitative research with a focus on character education that is built and applied to the millennial generation. The research method used is descriptive qualitative method. Data analysis was carried out descriptively. Serat Wulangreh were opened to determine the noble values contained in it, which was then concluded as the character values. The results of this study were the finding of appropriate text content as a source of character education for the millennial generation, including not to boast about their strength, nobility, and intelligence; not to feel pretentious; not easy being flattered and wanted to listen to advice; honest, patient, careful and vigilant; be selective in choosing friends; and also able to earn people's trust in a good way. These are the source of character education for the millennial generation as provisions for living life.
\end{abstract}

Keywords: moral values, noble values, character values, millennial generation 


\section{PENDAHULUAN}

Generasi milenial adalah generasi muzda saat ini yang hidup dan berkembang seiring sejalan dengan perkembangan teknologi informasi yang begitu pesat. Kondisi ini mempengaruhi pola pikir, gaya hidup, bahkan karakter dalam kehidupan sehari-hari. Dinamika perkembangan teknologi yang begitu cepat berpengaruh pada perilaku generasi muda yang tidak mencerminkan nilai-nilai filosofis dan karakter yang selama ini dijunjung tinggi sebagai budaya luhur bangsa Indonesia. Masa depan bangsa Indonesia ditentukan oleh generasi muda yang saat ini sedang tumbuh. Agar generasi muda tidak terjebak pada perilaku yang negatif maka generasi muda membutuhkan arahan agar tidak salah langkah dan tetap mempunyai filter diri yang kuat sebagai bekal penyaring berbagai macam informasi yang masuk agar tidak salah arah yang nantinya berpengaruh pada karakter suatu bangsa. Oleh karena itu Pendidikan karakter bagi generasi muda menjadi sangat penting dan harus terus - menerus dilakukan oleh semua pihak demi harapan dan masa depan bangsa Indonesia (Nasiruddin, 2017). Filter diri yang kuat merupakan kunci keberhasilan agar generasi muda memiliki karakter positif sebagai bekal hidup berbangsa dan bernegara. Karakter posistif yang bermuara pada kearifan lokal adalah kekuatan tersendiri agar generasi muda tetap berpijak pada nilai-nilai luhur yang dimiliki oleh bangsanyasendiri.

Kearifan lokal yang bisa dijadikan sebagai sumber pendidikan karakter adalah karya sastra. Karya sastra yang berisi nasehat disebut juga naskah piwulang oleh masyarakat Jawa di masa lampau dijadikan sebagai sumber perilaku hidup. Identitas dan jati diri orang Jawa terlihat pada gestur dan perilaku dengan berdasar pada ajaran masa lampau yang dipercaya memiliki nilai-nilai luhur dan budi pekerti budaya bangsa. (Nugroho et al., 2019).

Serat Wulang Reh dipilih sebagai objek material penelitian kerena didalam Serat Wulangreh diajarkan hakikat bagaimana menjadi manusia yang berbudi luhur baik dalam lingkup sosial dan hubunganya dengan Tuhan (Sri Yulita Pramulia Panani, 2019). Serat Wulangreh Pupuh Gambuh dipilih dalam penelitian ini karena nilai pesan yang terkandung didalamnya selaras dengan kehidupan anak muda di jaman sekarang. selain itu juga karena Serat Wulangreh dijadikan bahan ajar dalam pelajaran Bahasa Jawa tingkat SMP/MTs, dan pupuh Gambuh diajarkan di kelas VIII Semster Gasal. Dari sini terlihat bahwa generasi milenial yang sekarang duduk di bangku SMP/MTs adalah generasi sasaran agar mereka tetap berpijak pada kearifan lokal.

\section{Metode}

Metode penelitian yang digunakan adalah metode penelitian deskriptif kualitatif. Menurut Sugiyono (2008:15) menjelaskan bahwa penelitian deskriptif kualitatif adalah metode penelitian yang berlandaskan pada filsafat postpositivisme yang biasannya digunakan untuk meneliti pada kondisi objektif yang alamiah dimana peneliti berperan sebagai instrumen kunci. Proses analisis data dilakukan secara simultan yang mencakup klarifikasi, interpretasi dan analisis data. Analisis data dilakukan secara deskriptif (descriptive analysis) Hasil analisis data kemudian disajikan dalam bentuk laporan hasil penelitian (kesimpulan). 
Serat Wulangreh karya Sinuhun Pakubuwana IV Pupuh Gambuh sebagai objek penelitian, karena serat Wulangreh adalah salah satu karya besar yang dimasukkan kedalam kurikulum Mata Pelajaran Bahasa Jawa tingkat SMP/MTs di Jawa Tengah. Serat Wulangreh Pupuh Gambuh tercantum sebagai bahan ajar mata pelajaran Bahasa Jawa kelas VIII Semester Gasal. Selain itu juga karena di dalam Serat Wulangreh diajarkan hakekat bagaimana menjadi manusia yang berbudi luhur baik dalam lingkup sosial dan hubungannya dengan Tuhan (Sri Yulita Pramulia Panani, 2019). Penelitian ini bertujuan untuk menjelaskan dan mengungkapkan nilai luhur yang terkandung dalam serat Wulangreh pupuh Gambuh. Selanjutnya nilai luhur tersebut dijadikan sebagai sarana untuk mendidik karakter generasi milenial. Dengan demikian nilai-nilai luhuryang terkandung di dalam serat Wulangreh pupuh Gambuh tidak lenyap begitu saja, bahkan sebaliknya. Nilai luhur tersebut menjadi jati diri bangsa.

\section{Hasil}

Salah satu karya sastra klasik karya Sri Susuhunan Pakubuwana IV adalah Serat Wulangreh. Serat Wulangreh ditulis tahun 1768 - 1820, digubah dalam bentuk tembang macapat. Serat Wulangreh digubah dalam bentuk tembang macapat yang terdiri dari 13 pupuh. Pupuh ke-tiga adalah pupuh Gambuh. Pembahasan di sini fokus pada Pupuh Gambuh. Pupuh Gambuh merupakan materi Bahasa Jawa tingkat SMP/MTs kelas VIII, materi ajar yang dipelajari oleh generasi milenial. Tembang gambuh mempunyai watak: sumanak (ramah kepada siapapun), sumadulur (persaudaraan yang erat), mulang (mengajarkan), dan pitutur (nasehat).

Gambuh itu sendiri dimaknai dengan kecocokan, kesepahaman, dan sikap bijaksana. Dari hal tersebut dapat dimaknai dengan sikap bijaksana untuk menempatkan sesuatu pada tempatnya, sesuai dengan porsinya, dan mampu bersikap adil. Sesuai dengan karakter tembang Gambuh ini, maka tembang gambuh itu menggambarkan siklus kehidupan manusia memasuki masa muda masa indah masa menjelang pernikahan. Kata gambuh itu sendiri ada yang mengartikan dengan kata jumbuh, yang artinya cocok. Dari hal ini maka tembang gambuh itu cocok untuk memberi nasehat kepada anak-anaak muda.

Analisis isi ajaran moral Serat wulangreh perbaitnya dapat dijabarkan sebagai berikut.

\section{PUPUH III G A M B U H}

\begin{tabular}{ll}
\hline $\mathbf{0 1}$ & Artinya \\
\hline Sekar gambuh ping catur, & Tembang gambuh pola yang keempat, \\
Kang cinatur polah kang kalantur, & Yang dibahas adalah perilaku yang kebablasan, \\
Tanpa tutur katula-tula katali, & Tidak mau mendengar nasehat, \\
Kadaluwarsa katutuh, & Semakin lama semakin tak terkendali, \\
Kapatuh pan dadi awon. & Hal ini akan berakibat tidak baik. \\
\hline
\end{tabular}

Nilai moral yang terkandung dalam bait 1 sebagai bekal pendidikan karakter adalah bahwa orang yang tidak mau mendengar nasehat akan berakibat tidak baik. Untuk itu hendaknya kita 
senantiasa mendengarkan nasehat agar diri kita menjadi lebih baik.

Nilai karakter yang terkandung yaitu suka mendengarkan nasehat dari orang lain.

\begin{tabular}{ll}
\hline $\mathbf{0 2}$ & Artinya \\
\hline Aja nganti kebanjur, & Jangan sampai kau terlanjur, \\
Barang polah ingkang nora jujur, & Dengan polah tingkah laku yang tidak jujur, \\
Yen kebanjur sayekti kojur tan becik, & Jika sudah terlanjur akan mencelakakan, \\
Becik ngupayaa iku, ' & Dan hal itu tidak baik,oleh karena itu \\
Pitutur ingkang sayektos. & Berusahalah mencari ajaran yang benar. \\
\hline
\end{tabular}

Nilai moral yang terkandung dalam pada bait 02 adalah kita hendaknya berusaha dan menjaga agar jangan sampai berperilaku yang tidak jujur. Berperilaku yang tidak jujur jika sudah terlanjur melakukannya apalagi sudah menjadi kebiasaan akan mencelakakan diri sendiri.

Nilai karakter yang terkandung adalah sikap jujur.

\begin{tabular}{ll}
\hline $\mathbf{0 3}$ & Artinya \\
\hline Tutur bener puniku, & Nasehat yang benar itu, \\
Sayektine apantes tiniru, & Sesungguhnya patut untuk dicontoh, \\
Nadyan metu saking wong sudra & Walaupun nasehat itu berasal dari orang yang rendah \\
papeki, & derajatnya, \\
Lamun becik nggone muruk, & Namun, jika baik isi nasehatnya, \\
Iku pantes sira anngo. & Maka nasehat itu pantas kau pakai. \\
\hline
\end{tabular}

Nilai moral yang terkandung dalam bait 03 adalah hendaknya kita senantiasa mencontoh nasehat yang benar tanpa memandang siapa yang memberi nasehat. Jadi, nasehat itu dilihat dari isi nasehatnya bukan dari siapa yang memberi nasehat.

Nilai karakter yang termuat adalah mau mendengarkan dan melaksanakan nasehat yang baik dan benar.

\begin{tabular}{ll}
\hline $\mathbf{0 4}$ & Artinya \\
\hline Ana pocapanipun, & Ada kiasan yang bunyinya, \\
adiguna adigang adigung, & adiguna adigang adigung, \\
pan adigang kidang, & adigang dikiaskan kijang, \\
adigung pan esthi, & adigung dikiaskan gajah, \\
adiguna ula iku, & adiguna dikiaskan ular, \\
telu pisan mati sampyuh. & ketiganya mati bersama-sama. \\
\hline
\end{tabular}

Nilai moral yang termuat didalam bait 04 adalah sikap atau watak adigang adigung adiguna itu diibaratkan dengan hewan kijang, gajah, dan ular. Ketiga hewan tersebut pada akhirnya mati bersama-sama. 
Nilai karakter yang ada adalah jangan menyombongkan diri karena kesombongan itu akan membawa celaka.

\begin{tabular}{ll}
\hline $\mathbf{0 5}$ & Artinya \\
\hline Si kidang ambegipun, & Tabiat si kijang adalah, \\
angandelken kebat lumpatipun, & Menyombongkan kecepatannya berlari, \\
pan si gajah angandelken gung ainggil, & Si gajah menyombongkan tubuhnya yang tinggi besar, \\
ula ngandelaken iku, & Sedangkan si ular menyombongkan, \\
mandine kalamun nyakot. & bisanya yang ganas bila menggigit. \\
\hline
\end{tabular}

Nilai moral yang terkandung didalam bait 05 adalah kijang, gajah, dan ular menyombongkan kelebihannya masing-masing.

Nilai karakter yang diamanatkan adalah jangan menyombongkan diri akan kekakayaan, kekuasan dan kepandaian yang kita miliki.

\begin{tabular}{ll}
\hline $\mathbf{0 6}$ & Artinya \\
\hline Iku upamanipun, & Itu semua hanya perumpamaan, \\
aja ngandelaken sira iku, & Janganlah kau menyombongkan diri, \\
suteng nata iya sapa kumawani, & Karena putra raja sehingga tidak ada yang berani, \\
iku ambeke wong digang, & Itu tabiat orang yang adigang, \\
ing wasana dadi asor. & Ujung-ujungnya itu merendahkanmu. \\
\hline
\end{tabular}

Nilai moral yang terkandung di dalam bait 06 adalah janganlah kamu menyombongkan diri karena kamu anak orang yang memiliki jabatan sehingga kamu merasa tidak ada orang yang berani kepadamu. Sikap seperti itu termasuk watak adigang. Sikap seperti itu pada akhirnya hanya akan merendahkan diri kamu sendiri. miliki.

Nilai karakter yang terkandung adalah jangan menyombongkan kelebihan yang kita

\begin{tabular}{ll}
\hline $\mathbf{0 7}$ & Artinya \\
\hline Adiguna puniku, & Watak adiguna itu \\
ngendelaken kapinteranipun, & Menyombongkan kapandaiannya, \\
samubarang kabisan dipundheweki, & Seluruh kepandaian adalah miliknya, \\
sapa bisa kaya ingsun, & Siapa bisa seperti saya, \\
togging prana nora enjoh. & Padahal akhirnya tidak sanggup. \\
\hline
\end{tabular}

Nilai moral yang termuat di dalam bait 07 adalah bahwa orang yang menyombongkan diri karena merasa paling pandai dan menguasai segalanya, akan tetapi pada akhirnya dia tidak sanggup mengerjakan maka hal tersebut hanya akan membuat malu diri sendiri.

Nilai karakter yang terkandung adalah jangan suka menyombongkan kapandaian yang kita miliki. 


\begin{tabular}{ll}
\hline $\mathbf{0 8}$ & Artinya \\
\hline Ambek adigang iku, & Tabiat orang adigang itu, \\
angungasken ing kasuranipun, & menyombongkan keberaniannya, \\
para tantang candhala anyenyampahi, & semua ditantang berkelahi, \\
tinemenan nora pecus, & tetapi jika benar-benar dihadapi ia tidak akan melawan, \\
satemah dadi geguyon. & Akhirnya menjadi bahan tertawaan. \\
\hline
\end{tabular}

Nilai moral yang termuat dalam bait 08 adalah watak adigang itu adalah watak yang menyombongkan diri tentang keberaniannya. Merasa dirinya itu pemberani sehingga semua ditantang, akan tetapi ketika tantangannya itu diterima maka dia tidak sanggup melawan. Sikap seperti itu pada akhirnya menjadi bahan tertawaan orang.

Nilai karakter yang termuat adalah janganlah kita suka menyombongkan diri merasa paling pemberani. Sikap seperti itu hanya akan merendahkan diri sendiri.

\begin{tabular}{ll}
\hline $\mathbf{0 9}$ & Artinya \\
\hline Ing wong urip puniku, & Dalam kehidupan ini, \\
aja nganggo ambek kang tetelu, & janganlah kamu mengedepankan ketiga tabiat tersebut, \\
anganggoa rereh ririh ngati-ati, & berlakulah sabar, cermat, dan hati-hati, \\
den kawangwang barang laku, & perhatikanlah segala tingkah laku, \\
kang waskitha solahing wong. & waspadalah terhadap tingkah laku orang lain. \\
\hline
\end{tabular}

Nilai moral yang terkandung dalam bait 09 adalah kita hidup di dunia ini janganlah mempunyai ketiga watak: adigang, adigung, adiguna. Pakailah watak sabar, cermat, hati-hati, dan waspada terhadap segala perilaku orang lain.

Nilai karakter yang ada adalah sikap sabar, cermat, berhati-hati, dan waspada.

\begin{tabular}{ll}
\hline $\mathbf{1 0}$ & Artinya \\
\hline Dene tetelu iku, & Dari ketiganya itu, \\
si kidang ing patinipun, & Si kijang mati karena kegembiraannya, \\
pan si gajah alena patinireki, & Gajah mati karena keteledorannya, \\
si ula ing patinipun, & Sedangkan si ular \\
ngendelaken upase mandos. & mati karena keganasan bisanya. \\
\hline
\end{tabular}

Nilai moral yang terkandung di dalam bait 10 adalah seseorang yang menyomongkan diri pada akhirnya kesombongannya itu yang akan membawa kebinasaanya.

Nilai karakter yang terkandung adalah janganlah suka menyombongkan diri karena kesombongan itulah yang akan membinasakanmu. 


\begin{tabular}{ll}
\hline $\mathbf{1 1}$ & Artinya \\
\hline Tetelu nora patut, & Ketiganya tidak patut kau tiru, \\
yen tiniru mapan dadi luput, & kalau kau tiru akibatnya akan buruk, \\
titikane wong anom kurang wewadi, & ciri-ciri pemuda kurang kehati-hatiannya adalah, \\
bungah akeh wong kang nggunggung, & senang bila ada yang menyanjung, \\
wekasane kajalomprong. & akhirnya terjerumus. \\
\hline
\end{tabular}

Nilai moral yang terkandung di dalam bait 11 adalah ketiga sifat adigang, adigung, adiguna itu tidak pantas untuk ditiru. Jika ditiru akan berakibat tidak baik. Salah satu ciri pemuda yang kurang kewaspadaanya adalah senang jika ada orang yang menyanjungnya. Hal ini akan membuat dia terjerumus kedalam perilaku yang tidak baik.

Nilai karakter yang diajarkan adalah janganlah suka disanjung, karena sanjungan itu akan menjerumuskan kedalam hal yang tidak baik.

\begin{tabular}{ll}
\hline $\mathbf{1 2}$ & Artinya \\
\hline Yen wong anom iku, & Jika pemuda itu, \\
Kakehen panggunggung, & terlalu banyak sanjungan, \\
Dadi kumprung, & Maka ia menjadi tolol, \\
Pengung bingung wekasane pan $\quad$ Tuli dan bingung akhirnya mudah terombang-ambing, \\
angoling, & Jika sedang dipuji, \\
Yen ginunggung muncu-muncu, & Maka monyong-monyong seperti bisul yang hampir \\
Kaya wudun meh mecotot. & meletus. \\
\hline
\end{tabular}

Nilai moral yang terkandung di dalam bait 12 yaitu: jadi pemuda itu jangan mudah termakan sanjungan. Jika pemuda banyak disanjung maka dia akan menjadi tolol, bisu dan tuli yang akhirnya akan mudah terombang-ambing. Jika sedang dipuji kesenangannya diibaratkan seperti bisul yang hendak pecah.

Nilai karakter yang diajarkan adalah jangan suka disanjung.

\begin{tabular}{ll}
\hline $\mathbf{1 3}$ & Artinya \\
\hline Dene kang padha nggunggung, & Adapun yang senang menyanjung \\
pan sepele iku pamrihipun, & sangat sederhana keinginannya, \\
mung warege wadhuk kalimising lathi, & yaitu kenyang perut, basah lidah \\
lan telese gondhangipun, & Dan basahnya tenggorokan \\
reruba alaning uwong. & dengan menjual keburukan orang lain. \\
\hline
\end{tabular}

Nilai moral yang terkandng didalamnya adalah bahwa orang yang suka menyanjung itu, dia mempunyai tujuan tertentu. Tujuannya hanyalah sederhana yaitu dia hanya mengharapkan makan dengan cara menceritakan kejelekan orang lain. Hal ini sungguh perilaku yang tidak baik.

Nilai karakter yang bisa diambil adalah jangan suka menceritakan kejelekan orang lain hanya demi mendapatkan sesuatu. 


\begin{tabular}{ll}
\hline $\mathbf{1 4}$ & Artinya \\
\hline Amrih pareke iku, & Supaya dekat (dengan atasan). \\
yen wus kanggep nuli gawe umuk, & Jika sudah terpakai kemudian dia banyak membual \\
pan wong akeh sayektine padha wedi, & Kepada banyak orang supaya orang menjadi takut \\
tan wurung tanpa pisungsung, & Pada akhirnya dia tidak menerima pemberian apa-apa \\
adol sanggup sakehing wong. & dari hasil membual menjual kemampuan orang lain \\
\hline
\end{tabular}

Nilai moral yang terkandung di dalam bait 14 adalah apa yang dilakukannya itu yaitu menyanjung orang lain dengan cara menceritakan kejelekan orang lain adalah cara dia agar bisa dekat dengan atasan. Setelah dekat dia mengharapkan sesuatu, yaitu agar dia terpakai. Akan tetapi, setelah terpakai dia banyak membual agar orang lain takut kepadanya. Pada akhirnya dari keadaan itu dia tidak mendapatkan apa-apa. Perilaku ini adalah perilaku yang tidak baik dan tidak patut dicontoh.

Nilai karakter yang bisa diambil adalah hendaknya kita jangan melakukan berbagai cara hanya demi agar kita dianggap atau diakui oleh orang lain. Pada akhirnya kita tidak akan mendapatkan apapun dari perilaku itu.

\begin{tabular}{ll}
\hline $\mathbf{1 5}$ & Artinya \\
\hline Yen wong mangkono iku, & Orang seperti itu \\
nora pantes cedhak lan wong agung, & tidak pantas untuk berdekata dengan pembesar \\
nora wurung anuntun panggawe juti, & karena dapat mendorong untuk berbuat jahat. \\
nanging ana pantesipun, & Akan tetapi ada kepantasannya, \\
wong mangkono didhedheplok. & Orang seperti itu dinasehati dengan keras. \\
\hline
\end{tabular}

Nilai moral yang terkandung di dalam bait 15 adalah sebagai berikut. Orang yang seperti itu (suka meyanjung orang lain dengan tujuan agar dia dekat dan dipercaya oleh orang yang disanjung) adalah perilaku yang tidak baik. Orang yang seperti itu tidak pantas untuk berdekatan dengan pejabat, karena orang seperti itu dapat mendorong orang lain untuk berbuat jahat. Orang seperti itu sebaiknya diberi nasehat dengan keras.

Nilai karakter yang terkandung adalah selektif memilih teman.

\begin{tabular}{ll}
\hline $\mathbf{1 6}$ & Artinya \\
\hline Aja kakehan sanggup, & Jangan terlalu merasa tahu banyak. \\
durung weruh tuture agupruk, & Belum melihat dengan mata kepala sendiri tetapi \\
tutur nempil panganggepe wruh pribadi, & banyak berbicara, \\
pangrasane keh kang nggunggung, & bahkan hanya dengan mendengar seolah-olah \\
kang wus weruh amalengos. & mengetahui sendiri. \\
& $\begin{array}{l}\text { Dikiranya banyak yang menyanjung, } \\
\text { padahal yang mengetahuinya akan memalingkan } \\
\text { muka. }\end{array}$ \\
\hline
\end{tabular}

Nilai moral yang terkandung di dalam bait 16 adalah jangan mejadi orang yang banyak 
bicara merasa serba tahu. Apalagi hanya bermodal informasi dari orang lain yang belum tentu benar. Jangan berharap orang lain akan menyanjungmu dengan perilakumu yang seperti itu. Keadaannya justru sebaliknya. Jika hal itu dilakukan maka oaring lain yang sudah tahu akan memalingkan diri dari kita. Perilaku seperti ini tidak baik untuk dilakukan.

Nilai karakter yang terkandung adalah jangan merasa serba tahu.

\begin{tabular}{ll}
\hline $\mathbf{1 7}$ & Artinya \\
\hline Aja nganggo sireku, & Oleh karena itu, Nak. Jangan kau bersikap seperti itu \\
kalakuwan kang mangkono iku, & karena perilaku yang seperti itu, \\
nora wurung cinirenen den titeni, & pasti akan menjadi catatan dan perhatian, \\
mring pawong sanak sadulur, & dalam hati sanak saudara, \\
nora nana kang pitados. & mereka tidak akan percaya lagi kepadamu.(Widhi, n.d.) \\
\hline
\end{tabular}

Nilai moral yang terkandung di dalam bait 17 adalah janganlah kita berperilaku tidak terpuji. Perilaku tidak terpuji yang kita lakukan akan disoroti dan dijadikan catatan tersendiri oleh orang lain yang pada akhirnya orang lain tidak akan percaya lagi kepada kita. Orang lain akan menjauh dari kita.

Nilai karakter yang terkandung yaitu raihlah kepercayaan orang lain dengan cara yang baik.

\section{Pembahasan}

\section{GENERASI MILENIAL}

Anak-anak muda yang hidup di jaman sekarang ini termasuk kedalam golongan generasi milenial. Generasi milenial adalah generasi yang hidup di tengah kemajuan teknologi yang pesat. Hidup di tengah kemajuan teknologi yang pesat membawa manusia hidup kedalam kondisi tertentu. Kondisi tertentu itu diantaranya adalah mudah mendapatkan informasi dengan begitu cepat. Menghadapi kondisi yang seperti ini dibutuhkan kepribadian yang kuat agar tidak terjebak kedalam hal yang tidak diinginkan. Dari sinilah maka mempelajari serat Wulangreh pupuh Gambuh bagi generasi milenial adalah hal penting agar karakter generasi muda era milenial tetap berpijak pada kearifan lokal. Kearifan lokal ini didapat dari naskah-naskah lama yang masih tetap relevan dengan kondisi modern ini. Naskah lama yang dimaksud adalah serat Wulangreh karya Sri Susuhunan Pakubuwana IV, raja Kraton Surakarta.

Serat Wulangreh yang terdiri dari 13 pupuh dan pupuh ke tiga adalah pupuh Gambuh yang merupakan materi pembelajaran mata pelajaran Bahasa Jawa tingkat SMP/MTs di propinsi Jawa Tengah adalah salah satu yang harus dipahami oleh siswa SMP/MTs sebagai generasi milenial.

Dari uraian nilai moral dan nilai karakter yang terkandung dalam serat Wulangreh Pupuh Gambuh, maka generasi milenial hendaknya memiliki perilaku : suka mendengarkan nasehat dari 
orang lain,jujur, mau mendengarkan dan melaksanakan nasehat yang baik dan benar, jangan menyombongkan diri karena kesombongan itu akan membawa celaka, jangan menyombongkan diri akan kekakayaan, kekuasan dan kepandaian yang kita miliki, jangan menypmboongkan diri karena merasa paling pandai dan serba tahu, paling pemberani, jangan suka disanjung, jangan suka menceritakan kejelekan orang lain, jangan menghalalkan segala cara demi meraih tujuan. Hendaknya kita memiliki sikap sabar, cermat, hati-hati dan waspada, selektif memilih teman, meraih kepercayaan dengan cara yangbaik.

\section{Kesimpulan}

Serat Wulangreh pupuh Gambuh yang terdiri dari 17 bait mengandung nilai-nilai karakter yang bisa dijadikan sebagai rujukan dalam mendidik generasi muda jaman sekarang atau disebut juga generasi milenial. Adapun nilai karakter yang terkandung dalam serat Wulangreh pupuh Gambuh adalah Suka mendengarkan nasehat dari orang lain, jujur, mau mendengarkan dan melaksanakan nasehat yang baik dan benar, jangan menyombongkan diri karena kesombongan itu akan membawa celaka, jangan menyombongkan diri akan kekakayaan, kekuasan dan kepandaian yang kita miliki, jangan menyombongkan kelebihan ataupun menyombongkan apa yang kita miliki, jangan suka menyombongkan kapandaian yang kita miliki, janganlah kita suka menyombongkan diri merasa paling pemberani, sikap sabar, cermat, berhati-hati, dan waspada, janganlah suka menyombongkan diri karena kesombongan itulah yang akan membinasakanmu, janganlah suka disanjung, karena sanjungan itu akan menjerumuskan kedalam hal yang tidak baik, jangan suka disanjung, jangan suka menceritakan kejelekan orang lain hanya demi mendapatkan sesuatu, kita jangan melakukan berbagai cara hanya demi agar kita dianggap atau diakui oleh orang lain, selektif memilih teman, jangan merasa serba tahu, raihlah kepercayaan orang lain dengan cara yang baik.

\section{Referensi}

Darusuprapta. 1988. Serat Wulangreh anggitan dalem Sri Pakubuwana IV. PT. Citra Jaya Murti : Surabaya.

Daryanto, J.(2014). PENDIDIKAN KARAKTER DALAM PUPUH MIJIL SERAT WULANGREH KARYA PAKU BUWANA IV. Jurnal Pendidikan Dasar, 2(2). http://jurnal.fkip.uns.ac.id/index.php/diksar/article/view/5445

Lan, M., Pada, N., Membaca, P., Menulis, D. A. N., Utami, E. S., Jawa, S., Bahasa, F., \& Semarang, U.

N. (2019). Piwulang: Journal of Javanese Learning and Teaching. 7(2), 44-52.

Sri Yulita Pramulia Panani. (2019). Serat Wulangreh: Ajaran Keutamaan Moral Membangun Pribadi yang Luhur. Serat Wulangreh: Ajaran Keutamaan Moral Membangun Pribadi Yang Luhur, 29(2), 275-299. https://doi.org/10.22146/jf.47373

Widhi, H. (n.d.). Serat Wulangreh karya Pakubuwana II. 1-10. 
id.wikipedia.org/wiki/Serat_Wulangreh diakses hari Jumat tanggal 4 September 2020 pukul 22.22 WIB.

Nasiruddin. (2017). Peran Keluarga, Sekolah, dan Masyarakat dalam Pendidikan Karakter Generasi Muda Bangsa. Prosiding Seminar Nasional Tahunan Fakultas Ilmu Sosial Universitas Negeri Medan Tahun 2017, 1(1), 339-343. http://semnastafis.unimed.ac.id/wpcontent/uploads/2017/11/25.-NASIRUDIN.pdf

Fisika, J. P., Biologi, J. P., Kimia, J. P., \& Ganesha, U. P. (2013). 2165-3685-1-Sm. 2(2), 209220 .

Nugroho, Y. E., Widodo, W., \& Hardyanto, H. (2019). SERAT WULANG PUTRA SEBAGAI SUMBER PENDIDIKAN KARAKTER GENERASI MODERN (Serat Wulang Putra As a Source of Characters Education for Modern Generation). Alayasastra, 15(2), 141. https://doi.org/10.36567/aly.v15i2.409.

Sugiyono. (2008). Memahami Penelitian Kualitatif. .Bandung:Alfabet. 